\title{
BEM-BASED FORMULATION FOR THE ANALYSIS OF MULTI-STORY BUILDINGS INCLUDING SOIL- STRUCTURE INTERACTION
}

\author{
AHMED U. ABDELHADY ${ }^{1,2}$, AHMED FADY FARID ${ }^{2}$, YOUSSEF F. RASHED ${ }^{2}$ \& JASON MCCORMICK ${ }^{1}$ \\ ${ }^{1}$ Department of Civil and Environmental Engineering, University of Michigan, USA \\ ${ }^{2}$ Department of Structural Engineering, Cairo University, Egypt
}

\begin{abstract}
Modeling and analyzing multi-story buildings is an important part of structural engineering. Typically, this analysis is carried out using the finite element method by assembling the stiffness matrices of the floor elements and the vertical supporting elements at the intersecting nodes. Any consideration of soilstructure interaction (SSI) is often simplified using a Winkler model. However, the procedure for modeling practical buildings of complex geometries using the finite element method can be cumbersome. Alternatively, a new formulation that is based on the boundary element method (BEM) is presented that provides a seamless procedure for modeling practical buildings as the discretization of the floors is done at the floor perimeter and SSI is modeled using an elastic half space (EHS) model. The stiffness matrices of the slab and raft are generated using the BEM by introducing an additional collocation scheme at their intersection with the columns and the underlying soil. Columns are modeled as skeletal frame elements and the floors are considered as rigid diaphragms in their planes. Soil is modeled as an EHS and its stiffness matrix is derived based on the Bousinessq solution of an elastic, isotropic, homogenous, and infinite thickness half space. Assembly of the overall building stiffness matrix is carried out using the well-known assembly procedure associated with the stiffness analysis method. The proposed methodology is validated by comparing the results against the more traditional finite element approach. An illustrative example is solved showing agreement of the results between the proposed methodology and the finite element method.
\end{abstract}

Keywords: boundary element method, elastic half space, soil-structure interaction, multi-story buildings, stiffness analysis.

\section{INTRODUCTION}

There is a need to develop robust techniques for modeling and analyzing multi-story buildings. This need provides an opportunity for the use of the boundary element method, as a meshless technique, in modeling multi-story buildings while accounting for soil-structure interaction. Multi-story buildings consist of horizontal elements (e.g., slabs, beams, etc.) and vertical elements (e.g., columns, walls, etc.). The horizontal and vertical elements are supported above the ground by the foundation (e.g., raft, isolated footings, etc.).

The boundary element formulation of a flat plate supported by columns only is presented in [1]. Many researchers also worked on modeling a flat plate supported by beams using the boundary element method either based on Kirchhoff-Love plate theory [2], [3] or MindlinReissner plate theory [4], [5]. Edge beams are considered in the formulation presented by [2], [6] while in [5], [7] beams are modeled as a plate region with different thickness and material properties. In [4], a practical boundary element formulation is presented that can account for beams with any arbitrary configuration.

The problem of soil-structure interaction has been investigated extensively over the past few decades [8]-[12]. The analysis of a Mindlin-Reissner plate on an elastic half space (EHS) is presented in [8]. This analysis has been extended in [9] to account for the nonlinearity of the soil using an iterative procedure. A similar approach is presented in [10] to 
solve for a tensionless foundation. The analysis of the piled raft is presented in [11] where the pile-soil-raft interaction is considered.

In this work, a comprehensive methodology for the analysis of multi-story buildings including soil-structure interaction is presented. The presented methodology combines the use of the boundary element method to model the slabs and foundation raft, the elastic half space to model the underlying soil, and the stiffness analysis method. The presented methodology is applied to a three-story building and the results are validated using the finite element method.

\section{STIFFNESS ANALYSIS OF MULTI-STORY BUILDINGS}

Stiffness analysis has been widely used to analyze multi-story buildings under various loading conditions. The analysis applies Hooke's law which is stated as follows:

$$
\{\mathbf{P}\}=[\mathbf{K}]\{\mathbf{u}\},
$$

where $\{\mathbf{P}\}$ is the loading vector; $\{\mathbf{u}\}$ is the displacement vector; and $[\mathbf{K}]$ is the total stiffness matrix.

The total stiffness matrix $[\mathbf{K}]$ for the structure shown in Fig. 1 is obtained by assembling the stiffness matrices of the slabs, columns, raft, and soil. Columns are modeled using frame elements and their stiffness matrices are obtained as described in [13]. The slabs and raft are modeled using the Mindlin-Reissner plate bending theory while the supporting soil below the building raft is modeled as an elastic half space.

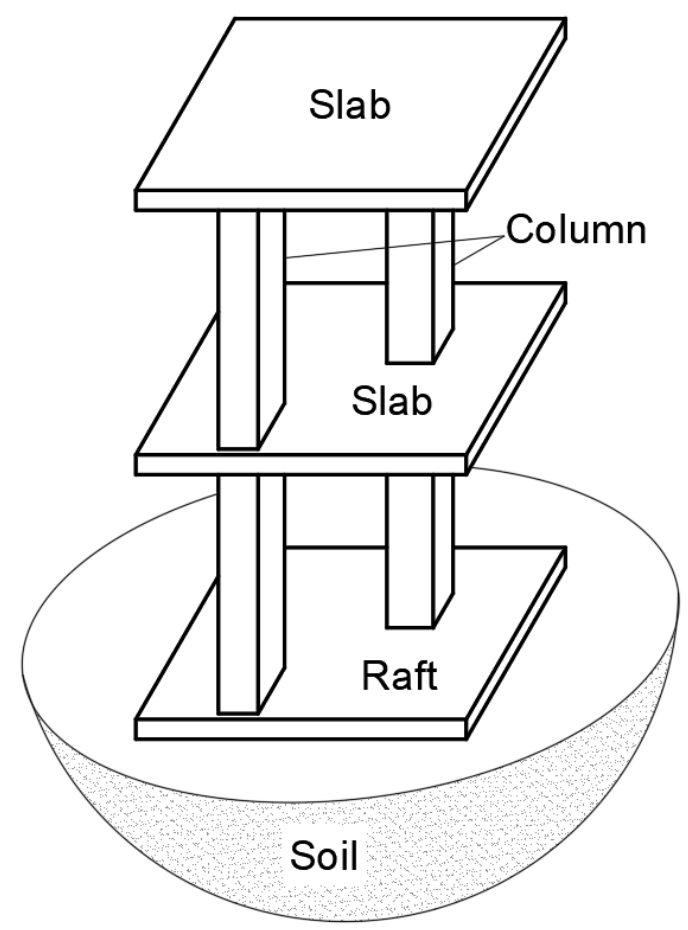

Figure 1: Schematic of the multi-story building under consideration. 


\section{SOIL STIFFNESS MATRIX}

The soil below the raft is modeled as an elastic half space (EHS), Fig. 2, and the stiffness matrix of the elastic half space is estimated as follows:

$$
\left[\mathbf{K}_{E H S}\right]=\left[\mathbf{F}_{E H S}\right]^{-1},
$$

where $\left[\mathbf{F}_{E H S}\right]$ is the flexibility matrix of the elastic half space.

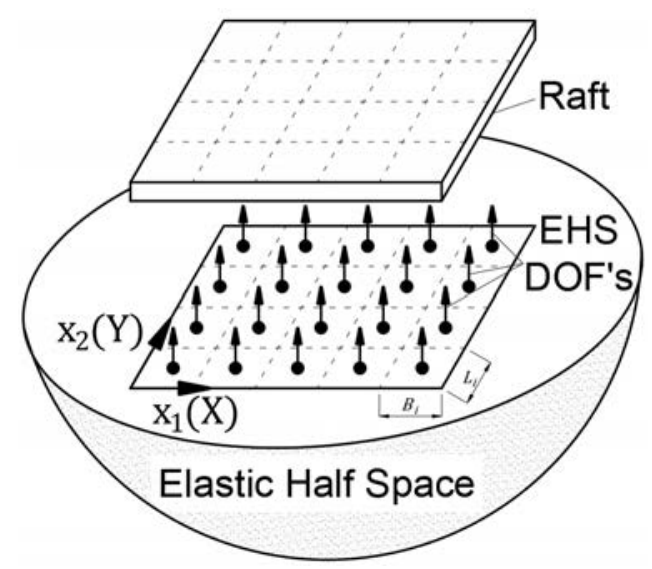

Figure 2: Raft on elastic half space.

The coefficients of $\left[\mathbf{F}_{E H S}\right]$ are calculated based on the Bousinessq solution [14] which provides the displacement of a point $(j)$ lying on the surface of an elastic, isotropic, homogenous, and infinite thickness half space due to a concentrated unit load at point $(i)$,

$$
f_{i j}=\frac{1-v}{2 \pi G r_{i j}} \quad \forall i \neq j
$$

where $f_{i j}$ represents the coefficients of $\left[\mathbf{F}_{E H S}\right] ; v$ is the Poisson's ratio; $G=E / 2(1+v)$ is the modulus of rigidity; $E$ is the modulus of elasticity; and $r_{i j}$ is the distance between the loading point $(i)$ and the displacement point $(j)$.

It should be noted that calculating the diagonal terms of $\left[\mathbf{F}_{E H S}\right]$ using eqn (3) (i.e., calculating the displacement at the concentrated load point) will lead to a singularity. This singularity is handled by replacing the concentrated load with an equivalent pressure that is distributed over the $i^{\text {th }}$ cell area $\left(B_{i} \times L_{i}\right)[8]$.

$$
f_{i i}=\frac{R_{i}(1-v)}{\pi G B_{i}}
$$

where $R_{i}$ is the rectangularity factor of the $i^{\text {th }}$ cell which is calculated as follows:

$$
R_{i}=\ln \left[\beta_{i}^{-\beta_{i}}\left(1+\sqrt{1+\beta_{i}^{2}}\right)^{\beta_{i}}\left(\beta_{i}+\sqrt{1+\beta_{i}^{2}}\right)\right]
$$

where $\beta_{i}=B_{i} / L_{i}$ is the rectangularity ratio. 


\section{MINDLIN-REISSNER PLATE STIFFNESS MATRIX}

The building slabs and raft are modeled using the Mindlin-Reissner plate bending theory. The boundary element method is used to solve the Mindlin-Reissner plate problem in order to generate the slabs' and raft's stiffness matrices.

\subsection{Boundary integral equation for a plate with internal supports}

Figs 3 and 4 show a boundary element model for a slab and raft, respectively. The indicial notation is used in this section where the Greek indices vary from 1 to 2 (to denote the $\mathrm{x}$ and $\mathrm{y}$ directions) and Roman indices vary from 1 to 3 (to denote the $\mathrm{x}, \mathrm{y}$, and the $\mathrm{z}$ directions). Slabs are modeled using Mindlin-Reissner plate bending theory where $\Gamma$ and $\Omega$ are the slab boundary and domain, respectively. The intersection area between the plate and the internal supports (i.e., columns and soil) are called supporting cells. Each supporting cell has a node located in its centroid. The direct boundary integral equation for a slab with supporting cells can be written as follows [4]:

$$
\begin{gathered}
C_{i j}(\xi) u_{j}(\xi)+\int_{\Gamma(\mathbf{x})} T_{i j}(\xi, \mathbf{x}) u_{j}(\mathbf{x}) d \Gamma(\mathbf{x})-\int_{\Gamma(\mathbf{x})} U_{i j}(\xi, \mathbf{x}) t_{j}(\mathbf{x}) d \Gamma(\mathbf{x})= \\
\sum_{N_{s}}\left[\int_{\Omega(s)}\left[U_{i k}(\xi, \mathbf{s})-\frac{v}{(1-v) \lambda^{2}} U_{i \alpha, \alpha}(\xi, \mathbf{s}) \delta_{3 k}\right] F_{k}(s) d \Omega(s)\right]
\end{gathered}
$$

where $C_{i j}$ is the jump term; $\boldsymbol{\xi}$ is the source boundary point; $\mathbf{x}$ is the field point; $T_{i j}$ and $U_{i j}$ are the fundamental solution kernels for traction and displacement, respectively; $t_{j}$ and $u_{j}$ are the boundary generalized traction and displacement, respectively; $N_{s}$ is the number of supporting cells; $\mathbf{s}$ is the centroid of the supporting cell; $\Omega(s)$ is the domain of the supporting cell; $v$ is the Poisson's ratio; $\lambda$ is the shear factor; $F_{k}$ is the interaction force between the supporting cell and the plate per unit area.

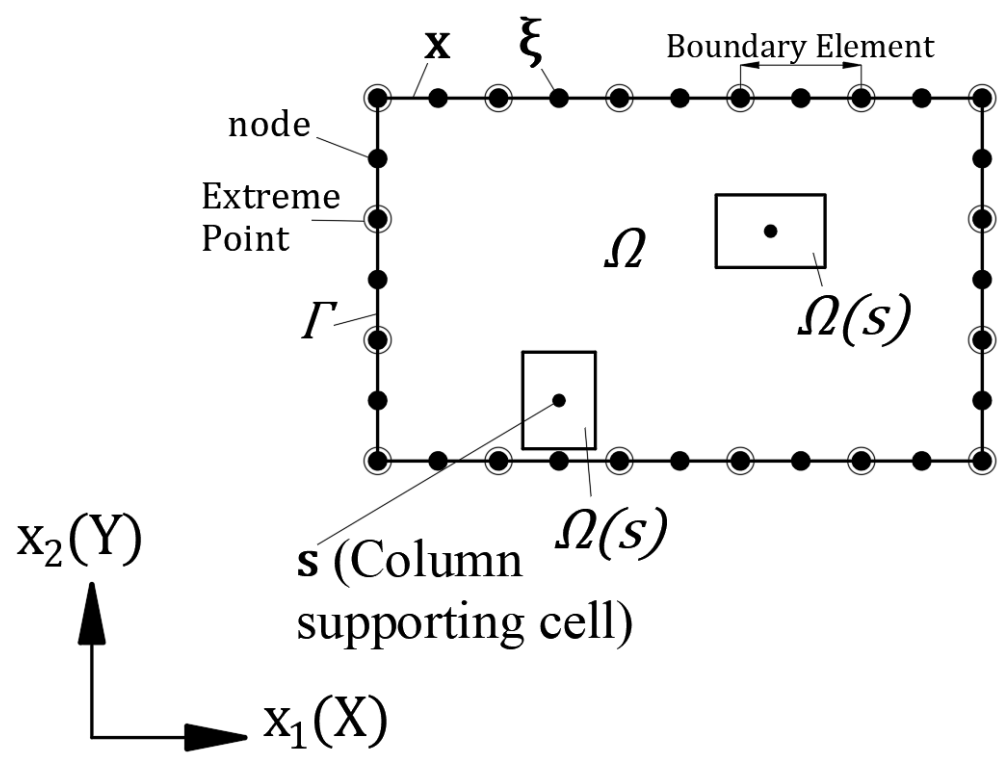

Figure 3: Slab boundary element discretization. 


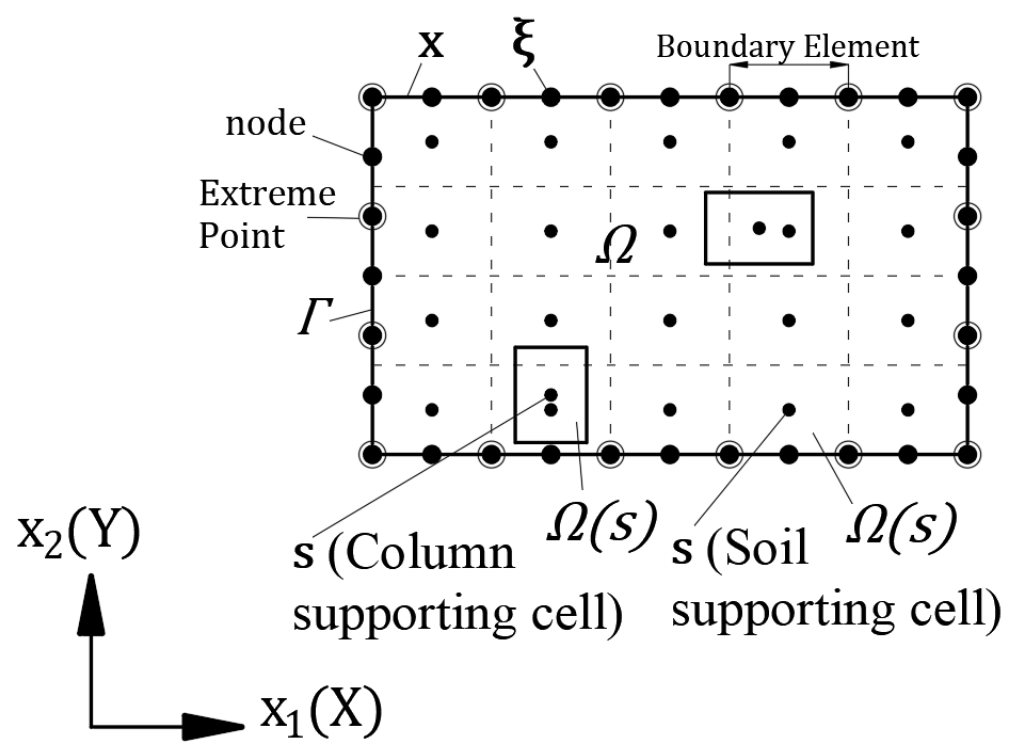

Figure 4: Raft boundary element discretization.

The plate boundary, Figs 3 and 4, is discretized into $N_{e}$ quadratic boundary elements. Then, the traditional collocation procedure is carried out at each boundary node which leads to the following matrix form of eqn (6):

$$
[\mathbf{A}(\xi, \mathbf{x})]_{3 N \times 3 N}\{\mathbf{u} / \mathbf{t}(\mathbf{x})\}_{3 N \times 1}=[\mathbf{B}(\xi, \mathbf{s})]_{3 N \times 3 N_{s}}\{\mathbf{F}(\mathrm{s})\}_{3 N_{s} \times 1},
$$

where $[\mathbf{A}(\boldsymbol{\xi}, \mathbf{x})]$ and $[\mathbf{B}(\boldsymbol{\xi}, \mathbf{s})]$ are the coefficient matrices obtained from the left hand side and right hand side of eqn (6), respectively; $\{\mathbf{u} / \mathbf{t}(\mathbf{x})\}$ is the vector of the unknown boundary displacements or tractions; $\{\mathbf{F}(\mathrm{s})\}$ is the vector of the forces at the supporting cells; $N$ is the number of the boundary nodes which equals $2 N_{e}$.

The unknowns in eqn (7) are $\{\mathbf{u} / \mathbf{t}(\mathbf{x})\}$ and $\{\mathbf{F}(\mathrm{s})\}$. The number of unknowns $\left(3 N+3 N_{s}\right)$ in eqn (7) is greater than the number of equations $(3 N)$. A solution strategy that is based on an additional collocation scheme pattern is proposed to solve eqn (7).

\subsection{Solution strategy}

The solution strategy uses an additional collocation scheme between the centroid of the supporting cells (s) as the source point and the slab boundary (x) as the field point.

$$
\begin{array}{r}
u_{j}(\mathbf{s})+\int_{\Gamma(\mathbf{x})} T_{i j}(\mathbf{s}, \mathbf{x}) u_{j}(\mathbf{x}) d \Gamma(\mathbf{x})-\int_{\Gamma(\mathbf{x})} U_{i j}(\mathbf{s}, \mathbf{x}) t_{j}(\mathbf{x}) d \Gamma(\mathbf{x})=\sum_{N_{s}}\left[\int _ { \Omega ( s ) } \left[U_{i k}(\mathbf{s}, \mathbf{s})-\right.\right. \\
\left.\left.\frac{v}{(1-v) \lambda^{2}} U_{i \alpha, \alpha}(\mathbf{s}, \mathbf{s}) \delta_{3 k}\right] F_{k}(s) d \Omega(s)\right] .
\end{array}
$$

Eqn (8) is then written in the following matrix form:

$$
\{\mathbf{u}(\mathbf{s})\}_{3 N_{S} \times 1}+[\mathbf{A}(\mathbf{s}, \mathbf{x})]_{3 N_{S} \times 3 N_{s}}\{\mathbf{u} / \mathbf{t}(\mathbf{x})\}_{3 N_{s} \times 1}=[\mathbf{B}(\mathbf{s}, \mathbf{s})]_{3 N_{S} \times 3 N_{s}}\{\mathbf{F}(\mathbf{s})\}_{3 N_{s} \times 1},
$$


where $[\mathbf{A}(\mathbf{s}, \mathbf{x})]$ and $[\mathbf{B}(\mathbf{s}, \mathbf{s})]$ are the coefficient matrices obtained from the left hand side and right hand side of eqn (8), respectively.

The additional collocation scheme generates additional equations that are combined with eqn (7) to balance the number of equations with the number of unknowns as follows:

$$
\left[\begin{array}{cc}
{[\mathbf{A}(\boldsymbol{\xi}, \mathbf{x})]_{3 N \times 3 N}} & -[\mathbf{B}(\boldsymbol{\xi}, \mathbf{s})]_{3 N \times 3 N_{S}} \\
{[\mathbf{A}(\mathbf{s}, \mathbf{x})]_{3 N_{S} \times 3 N_{S}}} & -[\mathbf{B}(\mathbf{s}, \mathbf{s})]_{3 N_{S} \times 3 N_{S}}
\end{array}\right]\left\{\begin{array}{c}
\{\mathbf{u} / \mathbf{t}(\mathbf{x})\}_{3 N \times 1} \\
\{\mathbf{F}(\mathbf{s})\}_{3 N_{S} \times 1}
\end{array}\right\}=\left\{\begin{array}{c}
\mathbf{0}_{3 N \times 1} \\
-\{\mathbf{u}(\mathbf{s})\}_{3 N_{S} \times 1}
\end{array}\right\} .
$$

\subsection{Stiffness matrix generation}

The slab and raft stiffness matrices are obtained by setting each generalized displacement in $\{\mathbf{u}(\mathbf{s})\}$ that corresponds to the degrees of freedom at the supporting cells to unity (one at a time). Eqn 10 is then solved. The resulting $\{\mathbf{F}(\mathbf{s})\}$ represents a column (or row) in the slab or raft stiffness matrix. The following equation summarizes this process:

$$
\left[\begin{array}{cc}
{[\mathbf{A}(\boldsymbol{\xi}, \mathbf{x})]_{3 N \times 3 N}} & -[\mathbf{B}(\boldsymbol{\xi}, \mathbf{s})]_{3 N \times 3 N_{S}} \\
{[\mathbf{A}(\mathbf{s}, \mathbf{x})]_{3 N_{S} \times 3 N_{S}}} & -[\mathbf{B}(\mathbf{s}, \mathbf{s})]_{3 N_{S} \times 3 N_{S}}
\end{array}\right]\left\{\begin{array}{c}
{[\mathbf{u} / \mathbf{t}(\mathbf{x})]_{3 N \times 3 N_{S}}} \\
{\left[\mathbf{K}_{s l a b}\right]_{3 N_{S} \times 3 N_{S}}}
\end{array}\right\}=\left\{\begin{array}{l}
\mathbf{0}_{3 N \times 3 N_{S}} \\
\mathbf{I}_{3 N_{S} \times 3 N_{S}}
\end{array}\right\},
$$

where I is the identity matrix; and $\mathbf{K}_{\text {slab }}$ is the slab stiffness matrix.

\section{APPLICATION}

In this section, the presented methodology is applied to analyze the multi-story building shown in Fig. 5. Analysis results are then compared with the finite element method (FEM) to validate the presented boundary element method approach.

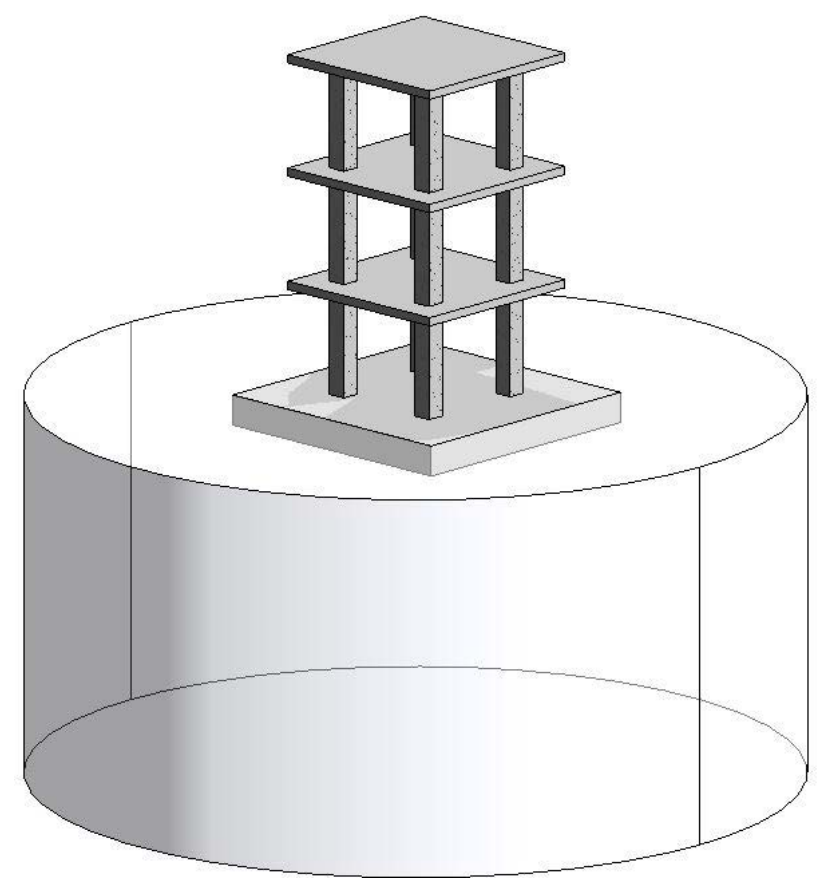

Figure 5: Structural system of the multi-story building. 


\subsection{Model description}

The considered multi-story building consists of three levels as shown in Fig. 5. Dimensions of the slab are $5 \times 5 \mathrm{~m}^{2}$ and its thickness is $0.25 \mathrm{~m}$. The slabs are supported by four columns which have a cross-section of $0.5 \times 0.5 \mathrm{~m}^{2}$. The four columns extend from the top slab to the raft which is $7 \times 7 \mathrm{~m}^{2}$ and its thickness is $0.8 \mathrm{~m}$.

The material used for the slabs, columns, and raft is concrete $\left(E=2.5 \times 10^{6} \mathrm{t} / \mathrm{m}^{2}\right.$ and $v=0.2$ ). The modulus elasticity of the soil is $10^{3} \mathrm{t} / \mathrm{m}^{2}$ while the Poisson's ratio is taken as 0.2 . The three slabs are loaded with a uniform load of $1.6 \mathrm{t} / \mathrm{m}^{2}$.

The boundary element models of a slab and raft are shown in Fig. 6. Fig. 7 shows the finite element model used to validate the results from the presented methodology [15]. The slabs and raft are modeled using Reissener plates, columns are modeled using frame elements, and the soil is modeled using solid elements. The size of the modeled soil block is $27 \times 27 \times 14 \mathrm{~m}^{3}$.

\subsection{Results and discussion}

Figs 8 and 9 compare the deflection $\left(u_{3}\right)$ obtained from the presented boundary element method approach and that from the finite element model for the top slab and the raft, respectively. The maximum deflection of the raft in the FEM is $19 \mathrm{~mm}$ which is around $5 \%$ less than the maximum deflection in the BEM $(20 \mathrm{~mm})$. For the top slab, the difference between the maximum and minimum deflection is $0.2 \mathrm{~mm}$ in the BEM which matches the results from the FEM with less than $1 \%$ difference.

Figs 10 and 11 compare the bending moment $\left(M_{11}\right)$ obtained from the BEM and the FEM for the top slab and the raft, respectively. The maximum negative moment, $M_{11}$, for the middle of the top slab in the BEM is $-0.731 \mathrm{t}$. $\mathrm{m}$ which is approximately $1.5 \%$ larger than the FEM $\left(-0.72\right.$ t. m). The maximum positive, $M_{11}$, for the top slab (at the column edge) in the BEM is $1.2 \mathrm{t} . \mathrm{m}$ which is $4 \%$ less than the FEM $(1.25 \mathrm{t.m})$. For the raft, Fig. 11, maximum negative and positive $M_{11}$ in the BEM and FEM vary within 2-5\% as well. These results validate the presented methodology as they show agreement between the BEM and the FEM.

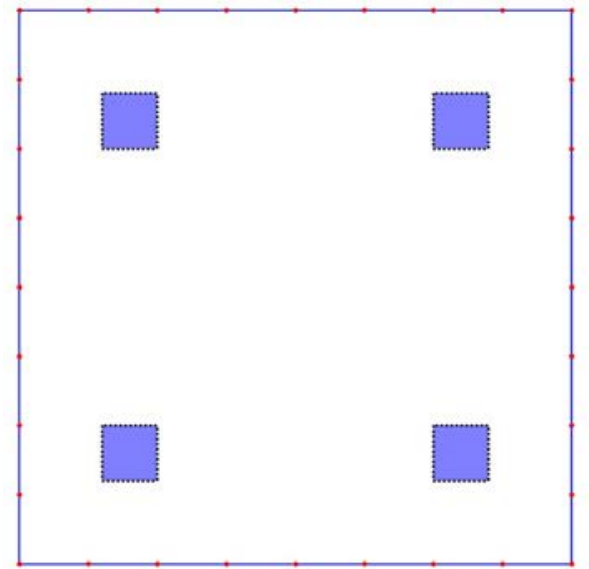

(a)

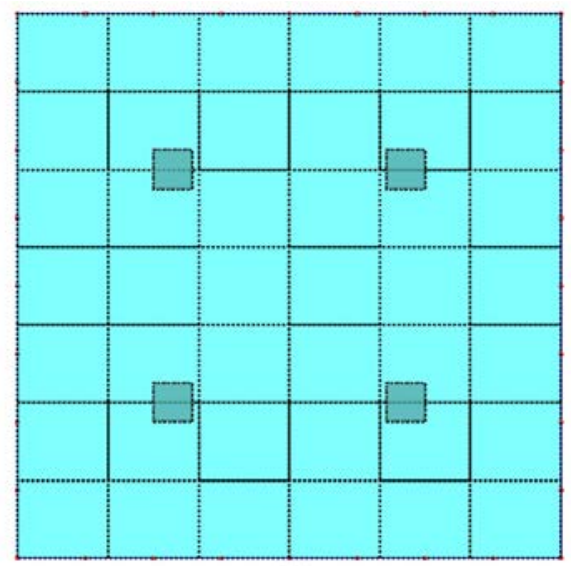

(b)

Figure 6: Boundary element model. (a) Slab; and (b) Raft. 


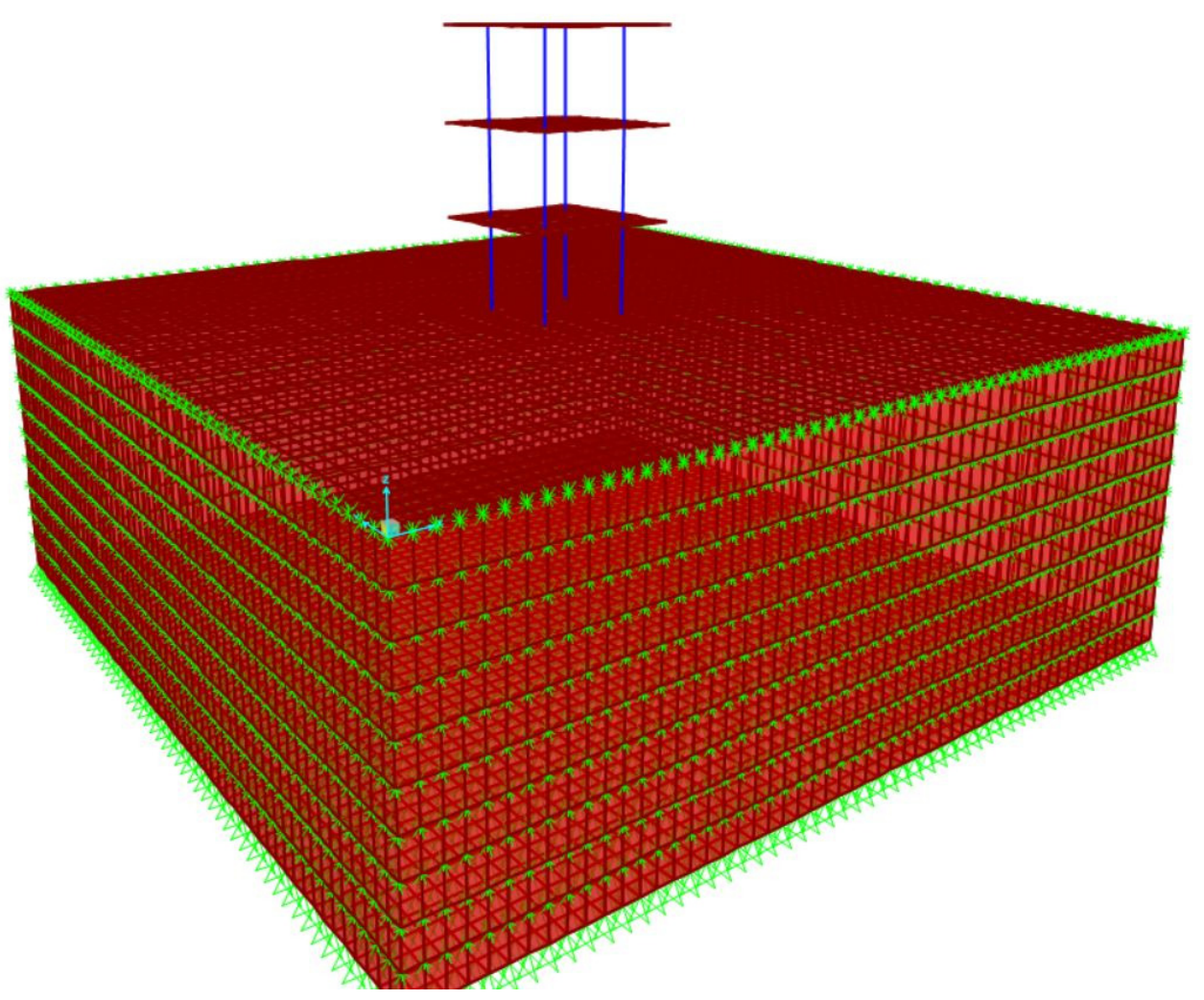

Figure 7: Three-dimensional finite element model for the building and the supporting soil.

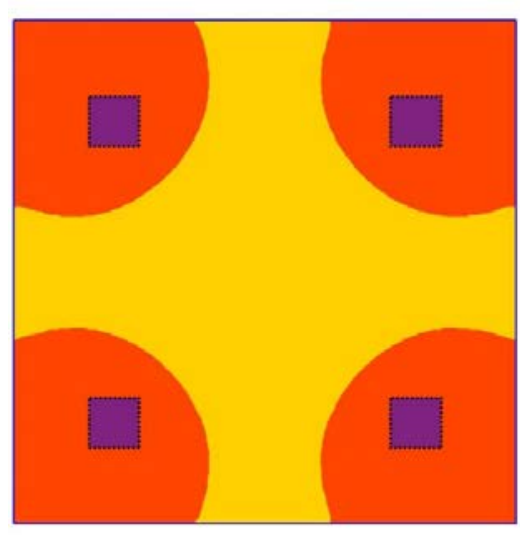

(a)
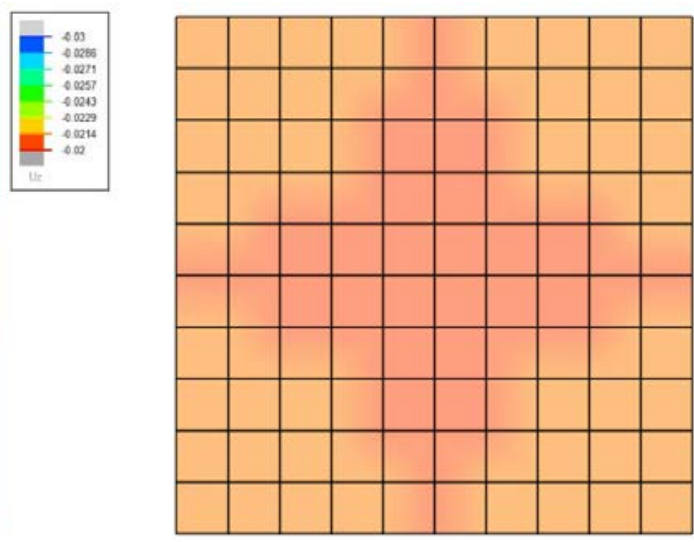

(b)

Figure 8: Top slab deflection $\left(u_{3}\right)$. (a) Presented methodology; and (b) Finite element method. 


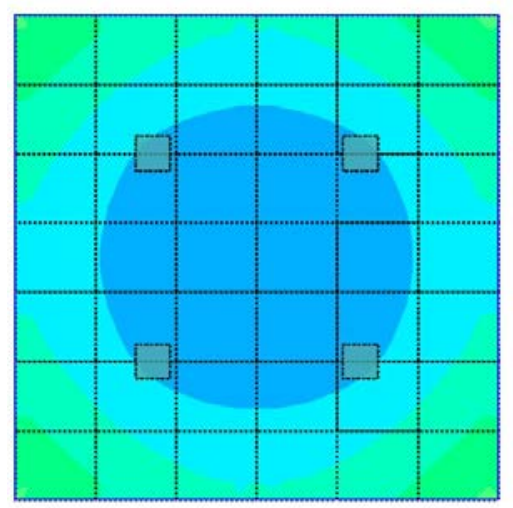

(a)
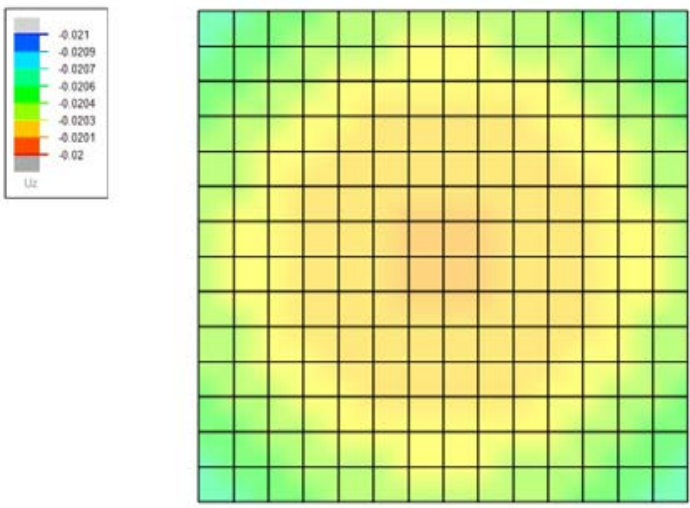

(b)

Figure 9: Raft deflection $\left(u_{3}\right)$. (a) Presented methodology; and (b) Finite element method.

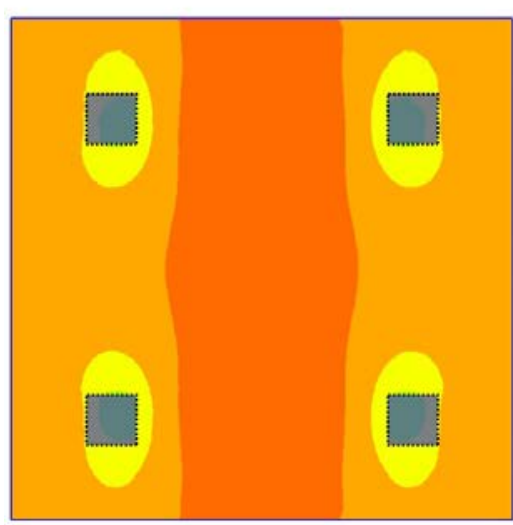

(a)

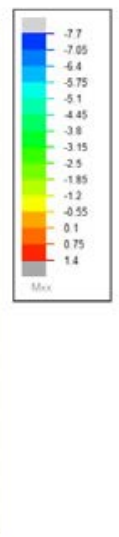

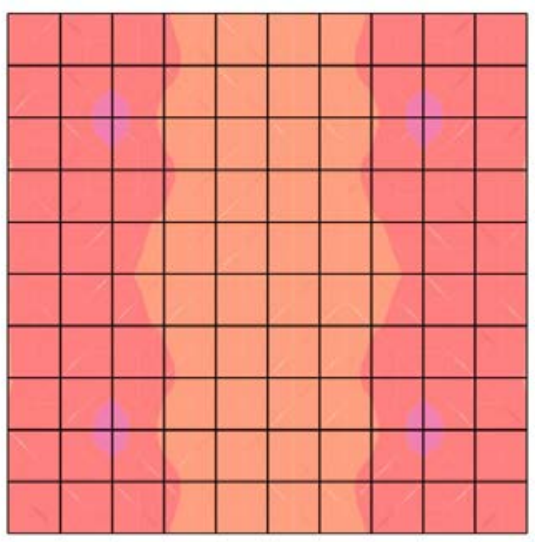

(b)

Figure 10: Top slab bending moment $\left(M_{11}\right)$. (a) Presented methodology; and (b) Finite element method.

\section{CONCLUSIONS}

This paper presents a methodology for the analysis of multi-story buildings including soilstructure interaction. The slabs and raft are modeled using a Mindlin-Reissener plate and their stiffness matrices are obtained using the boundary element method. Columns are modeled as frame elements and the soil is modeled as an elastic half space. The interaction between the soil and the building raft is handled using an internal support BEM-based formulation for the Mindlin-Reissener plate. Finally, the stiffness matrices of all building elements as well as the soil are assembled using the well-known technique of stiffness analysis method. The presented methodology is validated by comparing its results against the finite element method. 


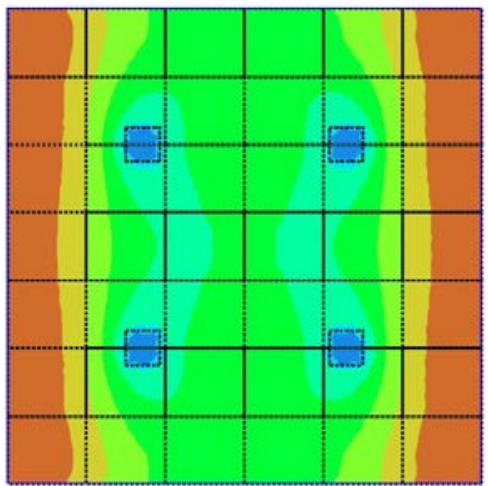

(a)
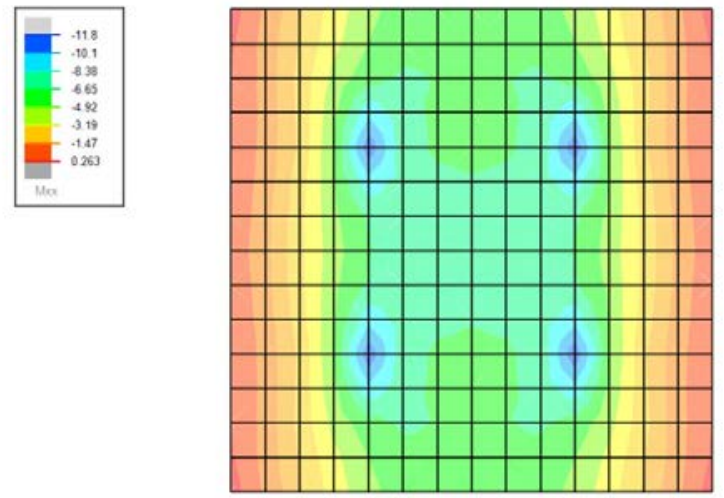

(b)

Figure 11: Raft bending moment $\left(M_{11}\right)$. (a) Presented methodology; and (b) Finite element method.

\section{REFERENCES}

[1] Rashed, Y.F., Boundary element modelling of flat plate floors under vertical loading. International Journal for Numerical Methods in Engineering, 62(12), pp. 1606-1635, 2005.

[2] Hu, C. \& Hartley, G.A., Elastic analysis of thin plates with beam supports. Engineering Analysis with Boundary Elements, 13, pp. 229-238, 1994.

[3] de Paiva, J.B., Boundary element formulation of building slabs. Engineering Analysis with Boundary Elements, 17, pp. 105-110, 1996.

[4] Abdelhady, A.U. \& Rashed, Y.F., A practical boundary element analysis of slab-beam floor type. Engineering Analysis with Boundary Elements, 97, pp. 23-38, 2018.

[5] Fernandes, G.R. \& Konda, D.H., A BEM formulation based on Reissner's hypothesis for analysing the coupled stretching-bending problem of building floor structures. Engineering Analysis with Boundary Elements, 36, pp. 1377-1388, 2012.

[6] Sapountzakis, J.T. \& Katsekadelis, J.T., Analysis of plates reinforced with beams. Computational Mechanics, 26, pp. 66-74, 2000.

[7] Fernandes, G.R., A BEM formulation for linear bending analysis of plates reinforced by beams considering different materials. Engineering Analysis with Boundary Elements, 33, pp. 1132-1140, 2009.

[8] Shaaban, A.M. \& Rashed, Y.F., A coupled BEM-stiffness matrix approach for analysis of shear deformable plates on elastic half space. Engineering Analysis with Boundary Elements, 37, pp. 699-707, 2013.

[9] Farid, A.F., Reda, M. \& Rashed, Y.F., Efficient analysis of plates on nonlinear foundations. Engineering Analysis with Boundary Elements, 83, pp. 1-24, 2017.

[10] Farid, A.F. \& Rashed, Y.F., BEM for thick plates on unilateral Winkler springs. Innovative Infrastructure Solutions, 3, p. 26, 2018.

[11] Shehata, O.E., Farid, A.F. \& Rashed, Y.F., Practical boundary element method for piled rafts. Engineering Analysis with Boundary Elements, 97, pp. 67-81, 2018.

[12] Azzam, O.A.A., Farid, A.F., Rashed, Y.F. \& Elghazaly, H.A., The use of out-of-core iterative solvers for large 3D soil problems. Engineering Analysis with Boundary Elements, 118, pp. 124-142, 2020. 
[13] Taranath, B.S., Structural Analysis and Design of Tall Buildings, McGraw-Hill: New York, USA, 1988.

[14] Selvadurai, A.P.S., Elastic Analysis of Soil Foundation Interaction, Elsevier: Amsterdam, 1979.

[15] CSI, CSI Analysis Reference Manual, Berkeley, California, 2016. 